Abstract FRI0325. Table 1.. * Analysed in MA of Souza 2016

\begin{tabular}{|c|c|c|c|c|c|c|c|c|c|}
\hline Author/year & Souza 2016 & $\begin{array}{l}\text { Devauchelle } \\
\text { 2014* }\end{array}$ & Meijer 2010* & Dass 2008* & Carubbi 2013 & Pipje 2005 & Gottenberg 2013 & Mekinian 2012 & Seror 2007 \\
\hline Study type (LOE) & $\begin{array}{c}\text { SR and MA } \\
(1+)\end{array}$ & $\mathrm{RCT}(1+)$ & RCT (1+) & RCT (1-) & $\begin{array}{c}\text { Not randomised } \\
(1-)\end{array}$ & $\begin{array}{c}\text { Not } \\
\text { controlled }^{3}\end{array}$ & Retrospective $^{3}$ & Retrospective $^{3}$ & Retrospective $^{3}$ \\
\hline Groups and N & $\begin{array}{c}\text { RTX } 145 / \mathrm{Pbo} \\
131\end{array}$ & $\begin{array}{l}\text { RTX 63/Pbo } \\
59\end{array}$ & $\begin{array}{l}\text { RTX 20/Pbo } \\
10\end{array}$ & $\begin{array}{l}\text { RTX 8/ } \\
\text { Pbo } 9\end{array}$ & $\begin{array}{c}\text { RTX 19/ } \\
\text { DMARDs22 }\end{array}$ & RTX 7 & RTX 86 & RTX 17 & RTX 16 \\
\hline \multicolumn{10}{|l|}{ Dryness: } \\
\hline VAS (oral, ocular, global). & - & - & - & & + & & & & \\
\hline Salivary flow & + & - & - & - & + & + & & & \\
\hline Schirmer & - & - & - & - & + & - & & & \\
\hline Lissamine green & & & + & & & & & & \\
\hline Rose Bengal & & & & & & + & & & \\
\hline TBUT & & & - & & & + & & & \\
\hline \multicolumn{10}{|l|}{ General and systemic manifestations: } \\
\hline ESSDAI & - & - & & & + & & + & + & \\
\hline SF-36 & - & - & - & - & & + & & & \\
\hline Fatigue VAS. & - & - & & - & + & + & & & \\
\hline Global VAS: patient/physician. & & $-/-$ & & & $+/+$ & & & & \\
\hline $\begin{array}{l}\text { Lab (IgG/A/M, beta2-microglobulin, RF, } \\
\text { B cells). }\end{array}$ & & + & + & + & & + & & & + \\
\hline Systemic: & & & + & & + & & + & + & \\
\hline
\end{tabular}

with placebo and a follow-up time of 6 months. The quality of the studies was assessed through the levels of evidence (LOE) of SIGN scale.

Results: The search resulted in a total of 749 articles and only 9 of them were selected (figure 1). The best available evidence for each variable studied is summarised in chart 1 ("+" significant improvement; "-" no significant improvement). The most relevant results obtained in the studies with LOE 1+, showed significant differences comparing RTX with lacebo $(p<0.05)$ in: 1) Souza 2016: Salivary flow rate at $24 \mathrm{w}$ (weeks) $(0.09 ; 95 \% \mathrm{Cl} 0.02$ to 0.16$)$. 2) Meijer 2010: Ocular dryness VAS score at $24(-27.00,95 \% \mathrm{Cl}-46.28$ to -7.72$), 36$ and $48 \mathrm{w}$. Lissamine green test at $24 \mathrm{w}(-2.00,95 \% \mathrm{Cl}-3.52$ to -0.48$)$. Absolute number of $\mathrm{B}$ cells from 5 to 48 w $(-0.23$; IC 95\%-0.31 to -0.15$)$. Rheumatoid Factor at 12, 24 and 36 w. Tendomyalgia at 12 and 36 w. Vasculitis at 24 w. 3) Devauchelle-Pensec 2014: 'mmunoglobulin's G (1.2 g/L; $95 \% \mathrm{Cl} 0.4$ to $2 \mathrm{~g} / \mathrm{L}), \mathrm{A}, \mathrm{M}$ and beta2-microglobulin $(1.6 \mathrm{~g} / \mathrm{L} ; 95 \% \mathrm{Cl} 0.5$ to $2 \mathrm{~g} / \mathrm{L})$ at $24 \mathrm{w}$. The studies with LOE 3 also report improvement in a percentage of patients in other systemic manifestations, but without demonstrating statistical significance.

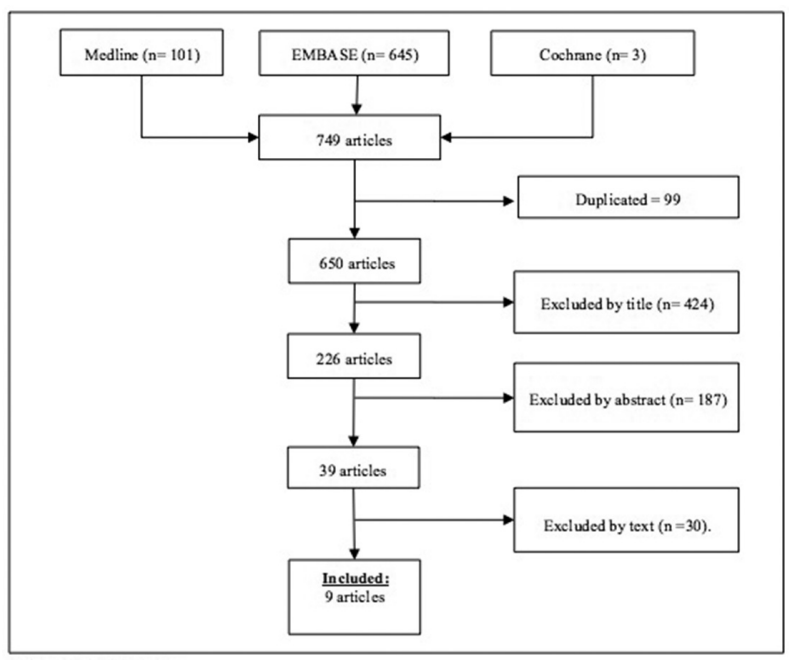

Abstract FRI0325 - Figure 1. Flow chart.

Conclusions: The studies of high methodological quality that evaluate the efficacy of RTX in pSS do not find significant improvement in the primary outcome variables, such as ESSDAI, glandular involvement and other objective parameters of dryness. However, open and retrospective studies find significant improvement in activity parameters, systemic manifestations, glandular involvement and improvement of certain objective tests of dryness.

Disclosure of Interest: None declared

DOI: 10.1136/annrheumdis-2018-eular.6914

\section{FRI0326 IMMUNE CELLULAR PROFILE ASSOCIATED WITH DIFFERENT TREATMENT OUTCOME IN PATIENTS WITH SYSTEMIC LUPUS ERYTHEMATOSUS ON CYCLOPHOSPHAMIDE}

G. Gabcova ${ }^{1}$, M. Skacelova ${ }^{2}$, Z. Mikulkova ${ }^{1}$, P. Horak $^{2}$, S. Zehnalova ${ }^{3}$,

A. Smrzova ${ }^{2}$, F. Mrazek ${ }^{1}$, V. Smotkova Kraiczova ${ }^{1}$, M. Kudelka ${ }^{3}$, E. Kriegova ${ }^{1}$.

${ }^{1}$ Department of Immunology, Palacky University Olomouc; ${ }^{2}$ Department of Internal Medicine III - Nephrology, Rheumatology and Endocrinology, Faculty of Medicine and Dentistry, Palacky University Olomouc, University Hospital, Olomouc,

Olomouc; ${ }^{3}$ Department of Computer Science, Faculty of Electrical Engineering and Computer Science, VSB-Technical University of Ostrava, Ostrava, Czech Republic

Background: Cyclophosphamide (CFA) is an effective immunosuppressive drug used for treatment of severe manifestations of systemic lupus erythematosus (SLE). The knowledge about modulatory effect of CFA on circulating immune cells and its changes associated with treatment response is limited.

Objectives: To determine the effect of a cumulative dose of CFA on circulating immune cells in SLE patients and to assess its association with treatment outcome.

Methods: Using 6-colour flow cytometry (BD FACSCanto II) we analysed T and B lymphocytes, NK cells, neutrophils, and monocytes in peripheral blood from 11 SLE female patients. SLE patients were investigated before and after cumulative $1000 \mathrm{mg}$ and $3000 \mathrm{mg}$ of CFA dose. Patients subgroups were assessed according to the treatment response ( $n=5$, good responders; $n=6$, poor responders); SLEDAI (Systemic Lupus Erythematosus Disease Activity Index) was used to assess the disease activity. Healthy age-matched females $(n=12)$ were included in the study. Statistics was done by GraphPad Prism and R statistical software package.

Results: Cumulative dose of $1000 \mathrm{mg}$ of CFA resulted in decreased percentage of $B$ lymphocytes $(p=0.0004)$ and CD4 + T lymphocytes $(p=0.02)$ and increased the percentage of total and CD8 + T lymphocytes $(p=0.03 ; p=0.0003$ respectively). After $3000 \mathrm{mg} C F A$, the percentage of $B$ lymphocytes $(p=0.002)$, naïve $B$ lymphocytes $(p=0.005)$, memory $B$ lymphocytes $(p=0.02)$ and CD4+/CD8 +ratio $(p=0.01)$ decreased while the percentage of CD8 $+T$ lymphocytes $(p=0.0003)$, Tregs $(p=0.01)$ and CD69 +NK cells $(p=0.02)$ increased. CFA treatment in our patients resulted in reduction of $B$ lymphocyte percentage reaching the values of healthy controls. In good responders, decreased percentage of $B$ lymphocytes $(p=0.04)$, CD4 +T lymphocytes $(p=0.04), C D 4+/ C D 8$ +ratio $(p=0.007)$ and increased percentage of CD8 +T lymphocytes $(p=0.004)$, CD69 +NK cells $(p=0.04)$ and nonclassical monocytes $(p=0.04)$. In poorly responding patients percentage of CD8 + T lymphocytes $(\mathrm{p}=0.01)$, activation marker HLA-DR on both CD4 +and CD8+T lymphocytes $(p=0.01 ; p=0.02$ respectively), Tregs $(p=0.02)$, memory $B$ lymphocytes $(p=0.03)$ were increased and percentage of total B lymphocytes was decreased $(p=0.02)$. The analysis using advanced data mining methods for identification of treatment outcome related profiles are ongoing

Conclusions: Administration of CFA modulates several cell populations in SLE patients, whereas changes in B and T lymphocytes were associated with different treatment outcome. Whether the immune profile may predict the treatment response deserves further investigation.

Acknowledgements: MZ CR VES15-28659A, IGA LF 2018016

Disclosure of Interest: None declared

DOI: 10.1136/annrheumdis-2018-eular.6180 